\title{
"WICKED OLD SOCIETIES": A PRESENÇA FRANCESA EM THE AGE OF INNOCENCE, DE EDITH WHARTON
}

\section{"WICKED OLD SOCIETIES": FRENCH PRESENCE IN EDITH WHARTON'S THE AGE OF INNOCENCE}

\author{
Rodrigo de Oliveira Lemos ${ }^{1}$
}

\begin{abstract}
Dans le fait, ces gens sages y exercent le plus ennuyeux despotisme; c'est à cause de ce vilain mot que le séjour des petites villes est insupportable pour qui a vécu dans cette grande république qu'on appelle Paris. La tyrannie de l'opinion, et quelle opinion! est aussi bête dans les petites villes de France qu'aux États-Unis d'Amérique.

Stendhal, Le rouge et le noir.
\end{abstract}

\begin{abstract}
RESUMO: The Age of Innocence (1920), de Edith Wharton, volta-se com ironia ao estranhamento entre o mundo anglo-saxônico e a França durante o século XIX. Para tanto, o romance se concentra na alta-sociedade nova-iorquina durante a Gilded Age (c. 18701900). Nessa história de um amor frustrado entre o rico e refinado Newland Archer e a americana Ellen Olenska, de volta aos Estados Unidos após abandonar seu marido na Europa, oferece-se um contraste entre a vitalidade artístico-literária do continente europeu, sobretudo de Paris, e a morosidade da vida intelectual na América de então. Igualmente, exploram-se os modos distintos de sociabilidade entre americanos e europeus, principalmente no que toca à convivência entre os sexos. Essas observações, além de comporem o pano de fundo da história, pesam no próprio desenrolar das relações entre os dois protagonistas e na maneira como ambos se encontram e se perdem.
\end{abstract}

PALAVRAS-CHAVE: Edith Wharton; The Age of Innocence; Cultura francesa.

ABSTRACT: The Age of Innocence (1920), by Edith Wharton, deals ironically with the estrangement between the Anglo-Saxon world and France during the nineteenth century. To this end, the novel focuses on New York high society during the Gilded Age (c. 1970 - 1900). In this story of a frustrated love between Newland Archer, a rich and refined gentleman, and Ellen Olenska, an American who is back in the United States after abandoning her husband in Europe, there is a contrast between the artistic and literary vitality of the European continent, especially in Paris, and the slowness of the intellectual life in America. Similarly, the different modes of sociability between Americans and Europeans are explored, particularly with respect to the mixing between the sexes. These observations, in addition to composing the story background, weigh on the unfolding of the relationship between the two protagonists and on how they both meet and loose each other.

KEY-WORDS: Edith Wharton; The Age of Innocence; French culture.

\footnotetext{
1 Doutor em Letras pela UFRGS e professor de Língua Francesa do Departamento de Educação e Humanidades da Universidade Federal de Ciências da Saúde de Porto Alegre (UFCSPA).
} 
As relações entre distantes e admiradoras do mundo anglo-saxão com as culturas do continente europeu, em especial as de origem latina, dentre as quais a francesa, foram amiúde objeto de representação literária e compõem por si só um linhagem na história literária na Inglaterra e nos Estados Unidos. Elas se tornam especialmente relevantes na literatura finissecular, enquanto Paris se consolida como capital do século XIX e os impérios britânicos e francês rivalizam em extensão e importância, ao mesmo tempo em que os Estados Unidos emergem como um jovem poder militar e industrial. Nessas condições, por certo que o vizinho inglês e o primo anglo-saxão de além-mar frequentaram as páginas dos autores franceses do período, nem sempre sob o olhar mais simpático. Des Esseintes, protagonista de $\grave{A}$ Rebours (romance de 1884 redigido por J.-K. Huysmans, que viria a se tornar o referencial da literatura decadentista francesa), entretém algo como uma simpatia literária pela Inglaterra de Dickens, e, no panteão do seu gosto, Edgar Allan Poe faz-se par de seu principal tradutor e divulgador na França, Charles Baudelaire (HUYSMANS, 1997, p. 246). Já a sociedade americana é eleita pelo neurastênico herói como símbolo do aviltamento da arte e da vida do espírito em favor do império do dinheiro, com o triunfo dos bancos e dos parvenus:

C'était le grand bagne de l'Amérique transporté sur notre continent ; c'était enfin, l'immense, la profonde, l'incommensurable goujaterie du financier et du parvenu, rayonnant, tel qu'un abject soleil, sur la ville idolâtre qui éjaculait, à plat ventre, d'impurs cantiques devant le tabernacle impie des banques ! (HUYSMANS, 1997, p. 268)

O vetor contrário da influência, da Paris capital de todas as modas e de todas as corrupções em direção ao mundo anglófono, não foi menos importante. Henry James foi um observador particularmente atento da civilização brilhante da capital francesa em romances como The Ambassadors (JAMES, 2002). Esse também é o caso no romance primo da antinarrativa de Huysmans que é The Picture of Dorian Gray, em que o próprio À Rebours - e a literatura simbolista que representa - surge como uma daquelas novidades intelectuais irradiadas das margens do Sena para, pelas mãos de Lord Henry, conspirar à delinquência moral e espiritual do jovem e belo protagonista:

There were in it metaphors as monstrous as orchids and as subtle in colour. The life of the senses was described in the terms of mystical philosophy. One hardly knew at times whether one was reading the spiritual ecstasies of some mediaeval saint or the morbid confessions of a modern sinner. It was a poisonous book. The heavy odour of incense seemed to cling about its pages and to trouble the brain. The mere cadence of the sentences, the subtle monotony of their music, so full as it 
was of complex refrains and movements elaborately repeated, produced in the mind of the lad, as he passed from chapter to chapter, a form of reverie, a malady of dreaming, that made him unconscious of the falling day and creeping shadows.

(WILDE, 2011, p. 89)

Escrito em 1920 pela americana Edith Wharton, The Age of Innocence situa-se na esteira dessas grandes narrativas oriundas do mundo anglófono em que Paris e a cultura francesa não apenas oferecem um pano de fundo para o transcorrer da ação, funcionando como um contraponto imaginário aos ditames, ao puritanismo e ao cant das sociedades americana ou inglesa; a capital francesa, bem como sua língua e sua cultura, têm um peso próprio, embora discreto, nesse enredo de amor insatisfeito e de vocações frustradas que tem lugar na alta-sociedade nova-iorquina durante a Gilded Age, aquela era de expansão econômica espetacular e de importantes desigualdades sociais pela qual se fecha o século XIX nos Estados Unidos. De fato, é o imaginário europeu, em especial o francês, que aproxima o advogado Newland Archer - jovem dotado de todas as benesses do dinheiro e de uma educação esmerada - da refinada émigrée americana Ellen Olenska, prima da sua convencional prometida, May Welland. Olenska retorna aos Estados Unidos, deixando para trás, por decisão própria, um marido na Europa, e tenta fazer-se aceitar pela recatada sociedade de Nova Iorque. Ao fim do romance, é igualmente na Europa, e em Paris, que a separação de Archer e de Olenska se consuma, como se o mundo americano e o francês jamais pudessem se encontrar. A trama do romance mostra em filigrana como uma história de amor impossível, ou impossibilitado pelas convenções da alta-sociedade americana finissecular, é perpassada constantemente pelo estranhamento entre esses dois mundos; por outro, adivinha-se o olhar retrospectivo e irônico de Edith Wharton sobre os modos ainda provincianos de uma Nova Iorque antiga em apenas alguns poucos decênios com relação à sua própria época.

\section{Uma sociedade da conversação}

Nova Iorque como um centro de artes e de vida intelectual - a imagem, talvez familiar ao leitor do século XXI, pouco tem a ver com a da cidade em que o amor de Newland e de Madame Olenska nasce e se frustra. Manhattan não parecia então um lugar atraente a quem buscasse os prazeres da palavra e do pensamento. É o que Newland, recémcasado com May Welland, sugere quando de sua viagem a Londres. Lá, o casal encontra, para a fascinação de Newland, Monsieur Rivière, homem de letras próximo aos Goncourt, aos Mérimée e aos Maupassant que integram o olimpo literário do jovem americano. 
Rivière, no entanto, está longe de gozar de uma posição social confortável. Francês filho de um empregado do serviço diplomático, tentara a vida no jornalismo, e daí na literatura (sem sucesso), até ver-se constrangido a uma vida de preceptor de crianças inglesas na Suíça e de secretário pessoal de ricos (é enquanto tal que ele se revelará a soldo do Conde Olenski, marido que Ellen abandonara na Europa). Ainda assim, malgrado sua precariedade, Newland o inveja por seu trânsito na vida das ideias, nisso distante de seu amigo novaiorquino Ned Winsett, igualmente desvalido, mas sem acesso ao bálsamo da troca intelectual para abrandar a sina de uma existência de privações:

He had obviously always been desperately poor and anxious (having a mother and an unmarried sister to provide for), and it was apparent that his literary ambitions had failed. His situation, in fact, seemed, materially speaking, no more brilliant that Ned Winsett's; but he had lived in a world in which, as he said, no one who loved ideas need hunger mentally. (WHARTON, 1996, p. 201).

Rivière vê a profissão de "private tutor" na velhice como "almost as chilling to the imagination as a second secretaryship at Bucharest" (Idem); sonda, então, Newland quanto a Nova Iorque e às possibilidades que o poderiam esperar na metrópole: "is not the intellectual life more active there?" (Ibidem). A reação de Archer é de estupefação, como se a própria associação de ideias entre Nova Iorque e a vida do espírito fosse de uma essencial incongruência:

\footnotetext{
Archer looked at him with startled eyes. New York, for a young man who had frequented the Goncourts and Flaubert, and who thought the life of ideas the only one worth living! He continued to stare at M. Riviere perplexedly, wondering how to tell him that his very superiorities and advantages would be the surest hindrance to success.

'New York - New York - but must it be especially New York?' he stammered, utterly unable to imagine what lucrative opening his native city could offer to a young man to whom good conversation appeared to be the only necessity. (WHARTON, 1996, p. 202)
}

Rivière concebe Nova Iorque segundo o modelo europeu de uma metrópole: um lugar de passagem e de encontro, que permite a sociabilidade entre homens de ideias imagem da qual a Paris do século XIX é o retrato insuperável, ainda que o mesmo estatuto não fosse estranho a outras capitais europeias. A realidade dos intelectuais da metrópole dos Estados Unidos dá-se melhor a conhecer na figura do contraponto americano de Rivière, Ned Winsett, o escritor frustrado que é amigo de Newland e que pergunta, uma noite, ao seu amigo rico e viajado, "with a little shiver, if the humanities were so meanly housed in other capitals", vindo a exclamar, bovaristicamente: "God, if I could emigrate!" (WHARTON, 1996, p. 122-124) 
A figura de Winsett representa o isolamento do intelectual na sociedade americana de fins do século XIX. Ele mesmo o admite: "I've got only one ware to produce, and there's no market for it here, and won't be in any time" (Idem, p. 123). Os intelectuais eram os chamados "fellows who wrote" (Ibidem, p. 101), mais os artistas e os pintores, e ficavam restritos ao seu pequeno círculo, em certas regiões da metrópole, à parte do restante da sociedade. Newland sabia que havia lugares em que os modos de encontro e de sociabilidade eram outros, "where painters and poets and novelists and men of science, and even great actors, were as sought after as Dukes". Sabia também que "even after his most exciting talks with Ned Winsett he always came away with the feeling that if his world was small, so was theirs, and that the only way to enlarge either was to reach a stage of manners where they would naturally merge" (Ibidem, p. 102). O estágio de costumes em que a elite social e a elite intelectual se encontrariam talvez estivesse por vir; em todo caso, ele já tinha um modelo no passado e no presente: a vida urbana parisiense.

O historiador Marc Fumaroli oferece um retrato dessa mundanidade parisiense em que são centrais a prática e o culto daquela conversação de que Ned Winsett se ressente em seu desterro nativo em Nova Iorque. A conversação como arte tem seu lugar de nascença na Paris do Antigo Regime, onde

\footnotetext{
elle avait trouvé l'une de ses formes les plus accomplies: elle y était devenue un jeu supérieur dont le public européen était le spectateur et accessoirement l'émule. Il y était exercé par des 'nobles' au surplus 'instruits', et qui jouissait entre eux, dans leur loisir et leur liberté, de cette confiance contagieuse, essentielle à l'esprit de conversation. (FUMAROLI, 1994, p. 122)
}

Essa associação de parceiros corresponde à formação de uma tribo formada por locutores exemplares e instruídos, nem eruditos, nem profissionais:

\footnotetext{
On y traite la parole en 'art libéral' parce qu'on y tient aussi et d'abord la lecture elle-même pour un art libéral. Ces locuteurs exemplaires ne sont ni des orateurs, ni des écrivains, ni des lecteurs érudits professionnels. L'esprit qui préside à leurs entretiens est incompatible avec le pédantisme des spécialistes. (FUMAROLI, 1994, p. 131)
}

Por certo, o culto da conversação como arte remete ao reino de Luís XIII (16101643), paralelamente à estabilização da corte em Paris e à língua literária de Malherbe ou de Guez de Balzac. Sob a égide de mulheres como Mme de Rambouillet, a princesa de Condé ou a condessa de Soissons, estabeleceu-se o ritual da conversação, com seus tons próprios, seus costumes, suas regras aos convivas reunidos pela arte do colóquio espirituoso. Nesse espaço privado que é o salão, pode-se, retomando a fórmula de Mme de Staël, fazer 
dialogarem nobres e homens de letras - a elite do poder e a elite do intelecto (FUMAROLI, 1994, p. 141). Essa tradição atravessa o Século das Luzes, em que brilham os nomes de Mme de Lambert e de Mme d'Épinay, suportes materiais e espirituais de vários dos principais pensadores iluministas (Idem, p. 152-172). O retorno da conversação de salão ao início do século XIX, durante a Restauração (1815-1830), assinala igualmente a reconstituição da vida intelectual após as trepidações da Revolução, e, durante o Segundo Império (1852-1870), ela se converte, de uma "arte liberal", em um código de classe, em sinal de pertencimento aos "círculos polidos", perdendo em vigor até ver suplantado o espaço do salão pelo do café ou do ateliê do artista (Ibidem, p. 173). Ainda assim, mesmo durante os anos finais do século XIX francês, a conversação de salão segue sendo um modo fundamental de sociabilidade entre as elites franceses, a qual encontrou em Marcel Proust um cronista e um observador ferino (PROUST, 1987).

É por certo esse estágio dos costumes, característico da França setecentista, que impressiona Newland, e ele percebe sua distância quanto aos Estados Unidos em fins do século XIX. Esse mundo da conversação mundana parisiense, já algo em vias de desintegração, distante das sutis elegâncias de sob o Antigo Regime, é por ele admirado num espírito de emulação. Significativamente, o próprio Rivière parece tão pouco encantado por esse universo cobiçado pelos americanos que cogita trocá-lo pelo deles. Trata-se de um modo de Wharton de sugerir uma espécie de insatisfação generalizada entre esses homens de espírito e de letras modernos, em busca de um alhures que os acolha por sentirem hostis ou deficientes as suas condições originais de vida numa sociedade mercantilizada? Ou eis aí mais uma de suas ironias quanto à vida na Nova Iorque do período, ao deixar entrever o bovarismo provinciano dos americanos, que teriam ainda por modelo idealizado um modo de sociabilidade há muito diluído?

\section{Um concerto de vozes mistas}

Se o tema da intelectualidade reflete a frustração de Newland na sociedade americana de fins do século XIX, o da condição feminina - que é, por certo, dos mais evidentes em The Age of Innocence - vem refletir as dificuldades e os desapontamentos da outra protagonista, Ellen. Esta e May Welland formam como um par de opostos tanto por sua rivalidade amorosa com relação a Newland quanto por aquilo que representam enquanto figuras do feminino: a noiva, May Welland, é a americana convencional e provinciana, como sugere sua falta de trato social durante o jantar na casa de Mrs. Carfry, em Londres 
(WHARTON, 1996, p. 199). Ellen, a amante manquée, figura, aos olhos da alta-sociedade nova-iorquina, a efígie não propriamente da mulher feminista, mas de costumes insólitos, pouco observadora das rígidas estratificações sociais da Nova Iorque da época. Ela é passível de desconfiança em uma sociedade como a nova-iorquina de então, gravada pelo puritanismo, por haver-se decidido a desertar um marido na Europa. Esse antagonismo caracterológico está longe de esgotar a gama de significado entre ambas, e é a doce e insípida May que toma a iniciativa de romper o laço platônico entre Newland e Ellen ao contar àquele sobre sua gravidez, ao passo que Ellen, por livre de convenções que pareça, detém-se diante da felicidade familiar da prima e daquele a quem ama.

Não nos enganemos, a suspeição em torno de Ellen decorre de seu caráter de "estrangeira" - ou melhor, de emigrada. Sobretudo, trata-se de uma emigrada europeia algo que se trai já na sua linguagem; Newland, francófono e francófilo, percebe em uma frase uma estrutura do francês a que ela devia estar mais habituada do que a expressão que seria mais natural em seu inglês nativo (WHARTON, 1996, p. 126). A Europa, e notadamente a França, constituem um universo à parte, de liberdades de modos desconhecidas em terras americanas, o que é perceptível mesmo nos detalhes da arquitetura. É assim quanto à casa de Manson Mingott:

Her visitors were startled and fascinated by the foreignness of this arrangement, which recalled scenes in French fiction, and architectural incentives to immorality such as the simple American had never dreamed of. That was how women with lovers lived in the wicked old societies, in apartments with all the rooms on one floor, and the indecent propinquities that their novels described (WHARTON, 1996, p. 26).

"Wicked old societies"; a permissividade de sociedades antigas como a francesa põe em suspeição qualquer mulher que se tenha formado nessa escola, tão mais ao se tratar de uma nativa que troca o velho modo de fazer americano pelos costumes duvidosos apreendidos além-mar. A mãe de Newland é categórica: "You mean, I suppose, that society here is not brilliant? You're right, I daresay, but we belong here, and people should respect our ways when they come among us. Ellen Olenska especially: she came back to get away from the kind of life people lead in brilliant societies" (WHARTON, 1996, p. 86). Embora assuma um outro ponto de vista moral, superficialmente admirador dos costumes mais livres das mulheres estrangeiras, Newland nem por isso deixa de reiterar o ponto de vista da mãe sobre o potencial dissolvente do modo de vida tradicional, mormente no que concerne às liberdades sexuais e afetivas das mulheres, inspirado pela vida em "ornamental societies" como as europeias: 
Rich and idle and ornamental societies must produce many more such situations; and there might even be one in which a woman naturally sensitive and aloof would yet, from the force of circumstances, from sheer defencelessness and loneliness, be drawn into a tie inexcusable by conventional standards. (WHARTON, 1996, p. 95)

Onde radica essa percepção, comum no século XIX, de uma relativa liberdade das mulheres francesas com relação às convenções sociais que pesavam sobre suas contrapartes de além da Mancha ou do Atlântico? A tradição francesa de galanteria tem sua importância sob esse aspecto, e o filósofo britânico David Hume, que permaneceu três anos (1763-1766) nos salões parisienses em plena efervescência iluminista, travando contato com Diderot, D'Alembert e d'Holbach (THE HUME SOCIETY, 2018), deixa algumas digressões sobre essa arte, que ele tem por um "natural produce of courts and monarchies" (HUME, 1882, p. 191), à imagem da França à época de sua estada. Ele funda o conceito de galanteria ao mesmo tempo na noção de progresso civilizatório e no caráter desigual das relações entre os sexos, com a força física e mental do homem sobrepujando a da mulher. No que Hume chama de nações bárbaras, a própria superioridade é a ocasião para que o homem ostente seu predomínio sobre a mulher; já nos países civilizados, assim como a polidez recomenda a deferência do mais novo, porque mais forte, quanto ao mais velho, ou ainda do nativo quanto ao forasteiro, porque sem defesa, assim também deve o homem "alleviate that superiority, as much as possible, by the generosity of his behaviour, and by a studied deference and complaisance for all her inclinations and opinions." (Idem, p. 193). Invenção moderna por excelência, a galanteria é um encanto desconhecido dos antigos, que relegavam o sexo feminino à esfera exclusivamente doméstica. Alienavam, assim, os encantos e o adoçamento dos costumes providos pela convivência com "virtuous women":

What better school for manners, than the company of virtuous women; where the mutual endeavour to please must insensibly polish the mind, where the example of the female softness and modesty must communicate itself to their admirers, and where the delicacy of that sex puts every one on his guard, lest he give offence by any breach of decency. (WHARTON, 1996, p. 194)

Essa tradição de galanteria, flagrada por Hume no século XVIII, não deixa sua marca sobre a imagem de Paris que conservam os heróis de Wharton? Ao mesmo tempo em que regrava as relações entre os sexos segundo uma concepção não igualitária e altamente ritualizada, a galanteria permitia tanto um contato constante e socialmente aceito entre homens e mulheres, frequentemente em situação amorosa, quanto uma certa preponderância, social assim como sentimental, do elemento feminino sobre o masculino. Cabia à "école des 
femmes" polir os homens, despi-los de sua brutalidade, de suas maneiras rudes, o que punha em ênfase o valor das mulheres como educadoras, mas igualmente como agentes no jogo do desejo; como lembra Claude Habib, até o advento da galanteria durante o reino de Luís XIV:

approcher des femmes touchait [...] à la profanation. La galanterie permettait au contraire d'approcher les femmes les plus belles, de leur parler d'amour toute la journée sans que cela soit un déshonneur pour personne. Elle laissait penser que l'on pouvait séjourner dans cette bulle de l'amour explicite et exprimé sans que cela n'ait de suite. (HABIB, 2018)

Nada dista mais desse jogo da mundanidade galante francesa do que o retrato da sociedade no romance de Wharton. O lugar da mulher é menos o salão onde a galhardia e o arrojo pautam a conversação entre os sexos, mas o ambiente familiar, o das ocupações domésticas, que ficavam especialmente sob sua alçada, como alguns lampejos da vida matrimonial de Newland Archer e de May Welland mostram bem:

\footnotetext{
"This lamp is smoking again; I should think the servants might see that it's kept properly trimmed," he grumbled nervously.

"I'm so sorry: it shan't happen again," she answered, in the firm bright tone she had learned from her mother; and it exasperated Archer to feel that she was already beginning to humour him like a younger Mr. Welland. She bent over to lower the wick, and as the light struck up on her white shoulders and the clear curves of her face he thought: "How young she is! For what endless years this life will have to go on!" (WHARTON, 1996, p. 268)
}

Fora do círculo familiar estrito, grande parte da sociabilidade da alta-roda novaiorquina se dá no pequeno círculo formado por outras famílias de boa sociedade: os Archer, os Welland, os Mingott, sobretudo os van der Luyden, que se encontram e socializam como que em clãs, em jantares ou na ópera. Trata-se de um ambiente recatado, muito menos propício à livre mistura entre os sexos, e a liberdade feminina se ressente dessa jaqueta por demais apertada. Outras formas de sociabilidade caem em suspeição, e, quando a notícia corre de que Olenska frequentou uma festa de Mrs. Lemuel Struthers, parvenue tida por vulgar, a mãe de Archer franze o cenho ao tratar do assunto com o filho: "All I know is, there was a woman who got up on a table and sang the things they sing at the places you go to in Paris. There was smoking and champagne." (WHARTON, 1996, p. 85). O ambiente, amplamente fantasmado pela elite americana, de licença e de dissolução da capital francesa basta a lançar uma sombra de suspeição sobre essas duas mulheres, tanto Lemuel Struthers quanto Mme Olenska, confirmando o que haveria de questionável nos costumes da emigrada, que surge como uma potencial intrusa. 


\section{Conclusão}

A constatação da rigidez de costumes e do conformismo reinantes nos Estados Unidos ao fim do século XIX não esperou uma americana como Edith Wharton para vir à luz. Precedendo em oitenta anos o romance de Wharton, um estrangeiro, e precisamente um francês, Alexis de Tocqueville, deixou um retrato acabado das normas sociais e dos costumes da sociedade americana em De la Démocratie en Amérique, cujo primeiro volume foi lançado em 1835 e o segundo em 1840. Nesse tratado sociológico que propõe uma descrição do sistema político americano dos anos 1830, quando Tocqueville, acompanhado de Gustave de Beaumont, visitou os Estados da costa leste, o autor não se restringiu a apresentar uma descrição das instituições do país; é toda uma antropologia do homem democrático, com suas crenças, seus gostos, seus preconceitos, que se descortina no retrato verossímil e perspicaz que Tocqueville oferece. Destaca-se, nesse retrato, a observação de que pesava sobre os americanos de então o espectro de uma tirania das maiorias (TOCQUEVILLE, 1990, vol. 1, p. 196). Nessa deriva possível de um sistema democrático como o americano, a opinião pública, que forma as maiorias; o legislativo, que a representa; o executivo, que é por ela nomeado; os júris, que são a maioria com poder de julgamento; enfim, os principais corpos sociais e políticos, porque imbuídos de uma vontade majoritária, correm o risco de terem seu poder amplificado, de se constituírem como uma voz coletiva, imperiosa e onipresente - uma voz tirânica em realidade, ao não suportar contrariedades. Esse fenômeno, próximo do que Stendhal denomina tirania da opinião (STENDHAL, 1990, p. 24), faz sentir seu peso especialmente sobre o pensamento, conformando-o a certas estereotipias e a certa rigidez moral que aparecem como sufocantes ao indivíduo, desaconselhado ao exame livre das opiniões majoritárias e, sobretudo, à expressão livre de sua análise, sob pena de sofrer as consequências do ostracismo:

On dirait, au premier abord, qu'en Amérique les esprits ont tous été formés sur le même modèle, tant ils suivent exactement les mêmes voies. L'étranger rencontre il est vrai, quelquefois des Américains qui s'écartent de la rigueur des formules; il arrive à ceux-là de déplorer le vice des lois, la versatilité de la démocratie, et son manque de lumières ; ils vont même souvent jusqu'à remarquer les défauts qui altèrent le caractère national, et ils indiquent les moyens qu'on pourrait prendre pour les corriger ; mais nul, excepté vous, ne les écoute; et vous, à qui ils confient ces pensées secrètes, vous n'êtes qu'un étranger, et vous passez. Ils vous livrent volontiers des vérités qui vous sont inutiles, et, descendus sur la place publique, ils tiennent un autre langage. (TOCQUEVILLE, 1990, p. 199) 
The Age of Innocence interessa-se, em um primeiro nível, pelas distinções sociais da velha sociedade nova-iorquina, dos aristocráticos Van der Luyden a outsiders e parvenus como Lemuel Struthers ou o banqueiro de origens obscuras Julius Beaufort. Entretanto, essas estratificações sociais não compõem um mosaico de sociedade de cores variegadas, feito de diversidade de sentimentos e de opiniões entre os diferentes meios e as diferentes classes - como pôde ser o caso, no passado, em sociedades rigidamente segmentadas segundo critérios de nascença, como as do Antigo Regime descritas por Tocqueville em L'Ancien Régime et la Révolution. (TOCQUEVILLE, 1985) Antes, a sociedade americana surge sob tintas monocromáticas: ela é a guardiã arredia de uma opinião ou de um costume, estando pronta a defendê-los a qualquer custo, o que faz eco àquela descrição de Tocqueville, décadas antes do romance de Wharton, sobre a tentação conformista dos homens nos Estados Unidos.

Tocqueville chama a atenção para o lugar do estrangeiro nessa sociedade ferozmente defensiva em suas opiniões feitas de um só bloco, por certo a partir de sua experiência como francês entre americanos. $\mathrm{O}$ estrangeiro ainda se beneficiaria de uma certa neutralidade, dada sua permanência precária na sociedade, que o torna insuspeito o suficiente para se tornar confidente para o exame crítico do país que alguns americanos se permitiriam discretamente, malgrado a tirania da opinião que não cessa de tecer loas ao solo americano: "vous n'êtes qu'un étranger, et vous passez". Ellen Olenska não goza desse estatuto. Não se trata propriamente de uma estrangeira, mas de uma americana que partira e que, a despeito de suas tentativas benevolentes de readaptar-se à sociedade local, é amiúde percebida como um objeto de suspeita contra o qual se devem defender as sentinelas dos padrões locais - um sentimento, de resto, expresso sem rodeios pela mãe de Newland. Tampouco sua estada se quer passageira; apesar de sua decisão final de retornar à Europa, seu objetivo primeiro era permanecer entre os parentes americanos, o que apenas faz crescer a pressão social para que ela desista da separação e retome seu casamento europeu. Finalmente, Newland, a despeito de suas visões pretensamente renovadoras, bebidas nos livros franceses e europeus, acaba por ajustar-se com perfeição ao molde social, tornando-se a efígie do cidadão americano impecável, suas simpatias anticonvencionais permanecendo no espaço íntimo à imagem daqueles americanos dissidentes encontrados por Tocqueville nos anos 1830 que "descendus sur la place publique, [...] tiennent un autre langage". Sob uma conformidade social tão esmagadora, sensível sobretudo à mulher e ao intelectual, a cultura francesa, encarnada em Paris, surge como um lugar fantasmado de evasão, mas igualmente como fonte inspiradora de uma qualquer mudança possível. 


\section{REFERENCIAS}

FUMAROLI, Marc. Trois institutions littéraires. Coll. Folio Essais. Paris: Gallimard, 1994. HABIB, Claude. La galanterie était le soft power de la monarchie française (entretien avec Antoine Lagadec). Revue des deux mondes. 9 février 2018. Disponível em: http://www.revuedesdeuxmondes. fr/claude-habib-galanterie-etait-soft-power-de-monarchiefrancaise/. Acesso em 28 de agosto de 2018.

HUME, David. Of the pise and Progress of the arts and sciences. Disponível em: https://davidhume.org/texts/rp/. Acesso em 28 de agosto de 2018.

HUYSMANS, J.-K. A rebours. Paris: Pocket, 1997.

JAMES, Henry. The ambassadors. Mineola: Dover, 2002.

PROUST, Marcel. Du côté de chez Swann. Coll. Folio Classique. Paris: Gallimard, 1987. STENDHAL, (H.-M. Beyle). Le rouge et le noir. Paris: Pocket, 1990.

THE HUME Society. David Hume's Life and Works. Disponível em: http://www.humesociety.org/about/HumeBiography.asp. Acesso em 28 de agosto de 2018. TOCQUEVILLE, Alexis. L'Ancien régime et la révolution. Coll. Folio Histoire. Paris: Gallimard, 1985.

. De la démocratie en Amérique, première édition historico-critique revue et augmentée par Eduardo Nolla. 2 volumes. Paris: Librairie Philosophique J. Vrin, 1990.

WHARTON, Edith. The age of innocence. London: Penguin, 1996.

WILDE, Oscar. The picture of Dorian Gray, ed. James Gifford. Victoria: McPherson Library, 2011. Disponível em: https://sites.ualberta.ca/ gifford/dorian/dorian.pdf. Acesso em 28 de agosto de 2018.

Recebido em 27/08/2018. Aceito em 19/10/2018. 